\title{
Diga-me com/para/por que(m) projetas...
}

\author{
Simone Diniz Junqueira Barbosa \\ Departamento de Informática \\ Pontifícia Universidade Católica do Rio de Janeiro (PUC-Rio) \\ simone@inf.puc-rio.br
}

\section{RESUMO}

... e direi o que produzes. Simples assim? Não! E ainda bem que não... Os modelos, métodos, frameworks e processos que escolhemos para nos apoiarem guiam e restringem nossa atenção e nossa atuação, mas não determinam o resultado. Podemos extrapolá-los, e com frequência devemos extrapolá-los, mas como? Conhecemos alguns marcos no caminho, como aprendizado básico, do bê-á-bá à prosa; e apropriação, da denotação à conotação, da prosa maçante à prosa elegante e prazerosa, à poesia. Mas nossas trajetórias são pessoais, cultivando hábitos como curiosidade e reflexão sobre o mundo em que vivemos -- indivíduos e sociedades, natureza e artefatos, seres humanos e algoritmos -- sob diferentes perspectivas e em diferentes níveis de abstração. Cada um de nós pode vestir vários chapéus, mas tem uma só cabeça. Mas somos muitos. E diversos. Vamos trabalhar?

\section{SHORT-BIO}

Simone Barbosa é professora do Departamento de Informática da Pontifícia Universidade Católica do Rio de Janeiro, onde ela leciona, orienta e conduz pesquisa na área de IHC. Ela é Bolsista de Produtividade em Pesquisa do CNPq - Nível 2, e seus interesses de pesquisa envolvem projeto de sistemas interativos baseados em modelo, ciência de dados, visualização de informações, storytelling digital e melhoria da qualidade de uso de sistemas interativos em diversos domínios, por meio de adaptação, mecanismos de analogia e outras técnicas de inteligência artificial. Ela é também coautora do livro-texto de IHC intitulado "Interação Humano-Computador" e membro do conselho editorial de vários periódicos, como Interacting with Computers, Journal of Interaction Science, Journal of Computer Languages, dentre outros. Em 2019, ela ganhou do International Federation for Information Processing Technical Committee on Human-Computer Interaction o IFIP TC13 Pioneer Award, pelo seu pioneirismo e contribuições para o crescimento da área de IHC.

Permission to reproduce or distribute, in whole or in part, material extracted from this work, verbatim, adapted or remixed, as well as the creation or production from the content of such work, is granted without fee for non-commercial use, provided that the original work is properly credited.

IHC 2020 - Plenárias, Outubro 26-30, 2020, Ciberespaço, Brasil. In Anais Estendidos do XIX Simpósio Brasileiro sobre Fatores Humanos em Sistemas Computacionais. Porto Alegre: SBC.

C 2020 by the author(s), in accordance with the terms of the Creative Commons Attribution-NonCommercial 4.0 International Public License (CC BY-NC 4.0)

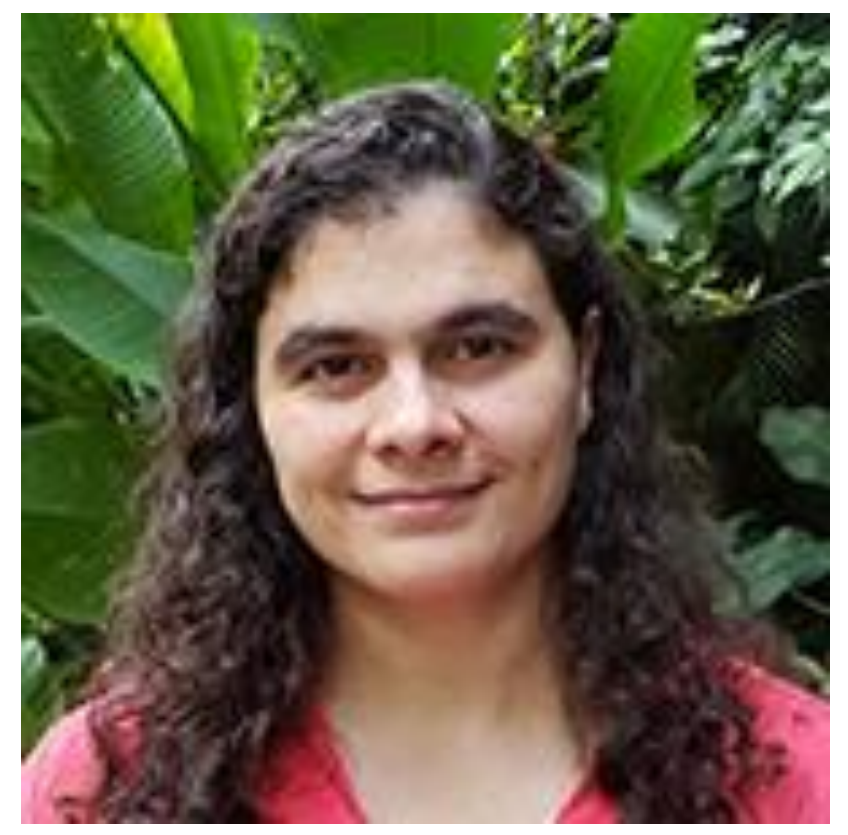

Figure 1. Simone Diniz Junqueira Barbosa 